\title{
Retailers' Differentiation Strategy and Pricing in the Rental Market of Digital Content: A Case of E-Textbooks
}

\section{Li Chen}

Fayetteville State University, College of Business and Economics, Department of Management, Marketing and Entrepreneurship, Fayetteville, NC, EE.UU., Ichen@uncfsu.edu

Received 5 April 2018; received in revised form 5 August 2018; accepted 26 September 2018

\begin{abstract}
Offering digital content for renting has become popular among online retailers. Following the trend, textbook retailers have introduced e-textbook rental programs which satisfy students' needs to reduce the cost of textbooks. Under the e-textbook rental model, retailers have homogeneous digital products and delivery channel. Therefore, they need specific differentiation strategies to distinguish themselves in the competition. In this study we aim to investigate the key factors of retailers' differentiation strategy and their impact on retailers' price advantage in the market. Our horizontal model shows that factors such as service quality are essential for the leading retailer to maintain price advantage in the competition. We also carry out an empirical study on service design and consumers' input by analyzing a unique data set of 151 e-textbooks from two major textbook rental retailers Amazon and Chegg. Our results show that factors including service flexibility, earliest return time, consumers' rating, and e-textbook selling price play a significant role in retailers' pricing differentiation strategy. Overall, our research provides useful managerial insights and operational policies for online textbook rental retailers.
\end{abstract}

Keywords: Digital content rental, Electronic textbook, Differentiation strategy, Regression analysis, Horizontal differentiation, Service quality 


\section{Introduction}

To monetize digital content, retailers have started to explore new methods such as renting models in recent years [35]. Several well-known examples are online newspapers (e.g. New York Times and Wall Street Journal), online video streaming services (e.g. Netflix), online music (e.g. Apple iTunes and Spotify), and software as a service (e.g. Salesforce). Under the renting model, consumers rent the digital products or services for a certain period of time instead of buying the perpetual ownership. Lambrecht et al. (2014) suggested that renting digital goods can be attractive models for consumers [34]. Rao (2015) pointed out that digital rights management (DRM) technology enables retailers to better control their digital goods as it could prevent them from being resold [44]. All these features contribute to the quick development and spread of rental services of digital goods.

Following the trend, retailers have introduced renting model in the market of electronic textbook (E-textbook) which has several features conducive to the development of the digital rental model. First, print textbooks are expensive and the possibility of lowering their prices remains elusive. Recent studies show that textbook prices increase twice as fast as inflation and students spend more than $\$ 1000$ on textbooks in a year [33]. Consequently, students' financial burden generates the demand for a less expensive digital rental market. Second, students often find that the rented print textbooks are in an unacceptable condition, and returning them or getting other textbooks usually incurs in an extra cost. Such risk cost is negligible if they rent e-textbooks. Third, e-textbooks are becoming more popular. Miller et al. (2013) suggested that the e-textbooks in business administration are well received by students [40]. DeNoyelles et al. (2015) found that the most important reasons for students to choose e-textbooks are low cost, convenience, and the feature of highlighting [18]. Now e-textbooks can be stored in multiple formats (PDF, ePub, DRM, and Kindle ebook format AZW) and can be read on multiple reading devices such as computers (PC and Mac), smart phones (iPhones and Android), and tablets (iPad and Amazon Fire). Overall, e-textbooks provide students easy access to study at their convenience, which leads to an increase in sales [45]. Fourth, besides print textbooks, publishers want to branch out into other forms of business to increase revenue, and introducing a rental model for their e-textbooks offers a promising future [41]

The e-textbook renting market has great potential for future development. Compared with the rental of other digital content, e-textbooks have several unique features. First, consumers often expect to get certain digital content such as online newspapers for free [5]. As a result, online newspapers need to balance the free content (advertising revenue) and paid content (renting revenue) [35]. Fortunately, consumers usually do not regard e-textbooks in the same way, which allows retailers to charge prices. Second, the subscription model such as Netflix usually provides older catalog titles in a collective library. Nevertheless, including premium titles by subscription is not feasible in the pay-per-use e-textbook rental industry. Third, retailers of physical goods such as print books often charge different fees for different delivery services as their price discrimination strategy [37]. On the contrary, e-textbook delivery is exactly the same: through the Internet. Therefore, there is little scope for retailers to distinguish themselves from the aspect of products and delivery, which requires them to develop other specific differentiation strategies.

Publishers provide access codes for students to use online supplemental resources such as homework modules, quizzes, and additional learning materials. Access codes can be bought separately or bundled with textbooks. Once activated, codes are usually attached to individual student and cannot be reused. Students usually cannot get these codes from used books or rental books. Therefore, when access codes are required in the class, students have no option but to purchase the codes from the university bookstore or the publisher. We believe access codes do not rule out the e-textbook rental market. According to a study from Student Public Interest Research Groups, students are required to use access codes in around one third of courses [9]. Therefore, students can find an alternative such as e-textbook rental in those courses not requiring access codes. In addition, the e-textbook rental market is still growing. According to an industry report from Technavio, the e-textbook rental market is expected to grow at almost $21 \%$ from 2017 to 2021 [7]

While renting model is not new in e-commerce, research so far has only offered some broad guidelines, rather than detailed insights, for digital content providers especially in the pay-per-use rental market. We haven't seen a standard of business practice for this new model. There is also a lack of rigorous research on the e-textbook renting retailers who share the homogeneous digital products and delivery channel. In this study, we strive to fill the gap by investigating how retailers try to gain competitive advantage with their differentiation strategy. To be more specific, we intend to answer the following research question: What are the key factors of retailers' differentiation strategy impacting their price competition, that is, how to get a price advantage in the market?

Using both a horizontal model and a unique dataset of 151 e-textbooks from two major retailers offering online etextbook rental program (Amazon and Chegg), we aim to carry out an exploratory study on the e-textbook rental market and give answers to the research question raised above. Our horizontal model shows that non-price factors such as service quality are essential for the leading retailer to maintain price advantage. Our empirical analysis suggests that the flexibility difference in retailers' rental service and the earliest return time (the earliest time renting ends) have a significant impact on the leading retailer's price differentiation. In addition, we find that consumers' rating as well as the e-textbook selling price contributes to the retailers' rental price difference. Our study has explored several understudied key drivers of the price difference, and offers insights for retailers into service design, 
consumers' ratings, and prices of competing formats in the market. The digital content renting market is undergoing rapid development. By providing retailers with useful managerial insights, we aim to help them build competitive advantages and thus a sustainable revenue model.

The rest of the paper is organized as follows. Section 2 provides a comprehensive literature review of relevant research. In Section 3, we propose our horizontal differentiation model between two retailers of e-textbook rentals which is inspired by real business market dynamics. In Section 4, we first briefly introduce the development of etextbook market then we develop a set of hypotheses related to retailers' differentiation strategy of pricing and test them with a unique dataset of 151 e-textbooks collected from two online textbook rental retailers (Amazon and Chegg). We present the regression analysis results and discuss the managerial insights based on our empirical analysis. Section 5 discusses the theoretical contributions and practical implications of our study. Section 6 concludes the paper with limitations and future research directions.

\section{Literature Review}

Our study is closely related to two research streams. The first stream can be found in literature that examines firms' renting models for digital goods and services. One group of study aims to find the optimal pricing method for the retailer, including monopoly software retailer [54], monopoly of information services [51], and online service providers [39]. In addition, Rao (2015) analyzed firms' strategy of selling or renting digital content to consumers [44]. She found that the retailer will benefit from serving only in the selling market if it is able to fix the price forever. However, if not, the firm should serve both the selling and the renting market. Overall, these studies suggest that the renting model can be a good choice for retailers. However, their findings do not provide detailed insights on how retailers develop their differentiation strategies in the digital renting market.

Another group of studies focuses on the subscription model of renting digital content. Han et al. (2015) showed that eBook consumers have benefit from an eBook subscription program, but their economic gain diminishes as consumers renew their subscriptions under the same contract duration [27]. This situation might arise from flat fee bias by which consumers overestimate the service usage. Oh et al. (2016) indicated that online newspaper publishers' subscription programs might lead to the long tail distribution of readers' content sharing (word of mouth) [42]. Lambrecht and Misra (2017) examined online content provider's strategy of providing free and paid content based on a dataset from ESPN [35]. They found that in general the firm should not provide just the paid content and suggested a dynamic adjustment of the amount of paid content across seasons. This group of study provides general strategies related to subscription model in areas of content management, readers' content sharing, and readers' economic gain.

Our study contributes to this line of literature in the following aspects: (1) Previous research on renting models of digital content mainly focuses on the subscription model which provides unlimited access to a relatively large collection for a period of time, such as renting a movie from Netflix. However, digital content renting is not limited to the subscription-based model. Our study explores the pay-per-use rental model, as in the case of e-textbook renting. So far research in this area is scarce. (2) Previous studies often examine retailers' pricing model decision or analyze retailers' strategy of digital content renting under the non-competing scenario. Little effort has been made to investigate retailers' differentiation strategy under the competition scenario. Li et al. (2017) analyzed the price competition of online content but in the setting of social media for investors [36]. Our study analyzes the impact of multiple important factors on retailers' price differences in the digital content renting market.

The second stream relates to the literature on pricing dispersion and price determinants in e-commerce upon which we develop the research instruments in our model. Prior research of price dispersion found that online retailers charge different prices for even homogeneous products (see detailed discussion in [14]). The widespread use of ecommerce channels does not lead to sellers' reduced price dispersion [43]. Factors that might explain these empirical findings can be classified into two categories: market friction and product differentiation [14]. Market friction refers to the conditions under which the market is not perfectly competitive. For example, retailers may provide incomplete information and increase search cost [24] or take advantage of consumers' limited memory [3]. However, strategies related to market friction such as increasing search cost and setting up high entry barriers don't fit the etextbook rental market. The search cost is lower in the online market. At the same time, retailers don't seem to experience high entry cost. With regard to product differentiation, conceptual models of previous studies suggest that retailers can well differentiate themselves by providing additional services such as pricing comparison tools, online customer reviews and recommendations, free shipping, and shorter service time. [12], [14], [19]. Other strategies include building the retailer's reputation among consumers [2], and most favorite customers (MFC) [30]. Overall, these studies highlight important differentiation strategies retailers use for price competition of homogeneous physical products. Since e-textbook rental delivery is through online channels with no shipping fees, free shipping or shorter service time may not apply in the digital content rental market. In addition, price comparison service and most favorite customers are rarely observed. Therefore, retailers need to identify applicable differentiation strategies related to e-textbook rental such as more flexible service options, and providing consumers' input.

In recent literature of price determinants, Doerr et al. (2010) conducted a survey of 132 online users of digital music streaming service (Maas) [22]. They found that contract duration, music quality, and distribution channel are the 
three most important aspects where consumers evaluate the service provided by Maas, which in turn, has a direct bearing on consumers' willingness to pay. Another study on the online music service from Wagner et al. (2014) pointed out that the free version can help promote the paid premium version of online music service [49]. The conceptual model of DiRusso et al. (2011) focused on the impact of consumer service, reputation and specialization [21]. They showed that specific factors such as service quality, return policy, and brand logo have positive and significant impact on the price differences. Similar results are reported in terms of service quality in the online gaming industry [29]. Based on data collected from Airbnb, Edelman and Luca (2014) showed that factors determining shared room price include the room features, consumers' ratings, social network function, and the race of the host [23]. The impact of consumers' rating on list price is also found in online markets [31]. A recent study, Teubner et al. (2017) analyzed the pricing of Airbnb from the aspect of trust [47]. Their results drawn from the pricing data in 86 German cities show that factors such as hosts' rating and duration of membership of the reputation system have a significant impact on price. In general, research in this literature stream shows that price determinants include retailers' service design and quality, reputation (consumers' rating), and product version. These findings provide useful references for retailers who are eager to locate key elements to develop their differentiation strategies such as rental duration, consumers' rating, and multiple product formats.

Drawing upon prior research, our study expands the literature by investigating the digital content rental market. This research context is fairly different from the direct selling model of physical products on e-commerce platforms because both the digital product and the delivery channel (of different service providers) are homogeneous. Doerr et al. (2010) studied determinants of consumers' valuation in the online music subscription service [22]. However, their study hasn't examined key factors of retailers' differentiation strategy for price advantage under the competition scenario. Many previous findings of product differentiation such as free delivery do not apply in this market. Therefore, we extend the conceptual framework of differentiation strategy by further exploring the new dimension of retailers' service design. We focus on the understudied factors such as service flexibility and earliest return time which are closely related to consumers' utility and evaluation of the e-textbook rental. In addition, we incorporate consumers' input and e-textbook selling price which comes from retailers' different practices. To the best of our knowledge, our study is the first to analyze e-textbook retailers' differentiation strategy and pricing in rental services.

Recent studies on e-books have mainly focused on the issue of the cannibalization effect of e-books on print books [6], [16], consumers' attitude toward e-books and print books [10], e-book pricing models [28], supply chain of e-book [38] and e-book sampling strategies [15]. Our study complements the existing research by investigating the retailers' differentiation strategy in the new business model of the e-textbook rental market.

\section{Model}

We examine in this section the e-textbook rental market served by two retailers (retailer $A$ and $B$ ) in the horizontal competition setting. We focus on the rental market rather than combining the selling market and the rental market for two reasons. First, previous studies have demonstrated that the rental market is growing into an independent market because it satisfies students' need for access to low-cost textbooks [8]. Second, the current setting enables us to avoid overcomplicated modeling and provide useful managerial insights for retailers in the e-textbook rental market.

Horizontal modeling is often used in research on digital goods and services [28], [32], [50]. Without loss of generality, we assume that retailer $\mathrm{A}$ is a leading retailer with brand name recognition $s_{A}$ and retailer $\mathrm{B}$ is a lesser-known retailer with a brand name recognition $s_{B}$ and $s_{A}>s_{B}$. This is inspired by the online book industry where Amazon is in a dominant position. Retailers' brand name recognition level might be related to factors other than prices such as service quality, additional information/service, and customer service. Modeling two types of firms is often used in prior research [16], [32], [48]. Consumers might choose retailers based on simplicity (convenience of purchasing other items together). However, this is beyond the research scope of our study. Table 1 below summarizes the variables used.

Table 1: Notations

\begin{tabular}{|l|l|c|l|}
\hline Notation & Definition & Notation & Definition \\
\hline$p_{A}^{e}, p_{B}^{e}$ & $\begin{array}{l}\text { Price of renting e-textbooks from retailer A and } \\
\mathrm{B}\end{array}$ & $S_{A}, S_{B}$ & Brand recognition of retailer A and B \\
\hline$\pi_{A}, \pi_{B}$ & Revenue of retailer A and B & $c_{e}$ & Inconvenience cost of e-textbooks \\
\hline$v$ & Reserved value & $k$ & Transportation cost \\
\hline
\end{tabular}

We assume that consumers are uniformly distributed on a Hotelling line segment $[0,1]$ with retailer $A$ located at zero $(0)$ and retailer $B$ anchored at one (1). Figure 1 presents the model. Consumers' utility of renting e-textbooks from retailer $\mathrm{A}$ is $v+s_{A}-k \theta-p_{A}^{e}-c_{e}$, and consumers' utility of renting e-textbooks from retailer $\mathrm{B}$ is $v+s_{B}-k(1-\theta)-$ $p_{B}^{e}-c_{e}$. Ultimately, each consumer decides which retailer to rent the textbook from based on his utility. 


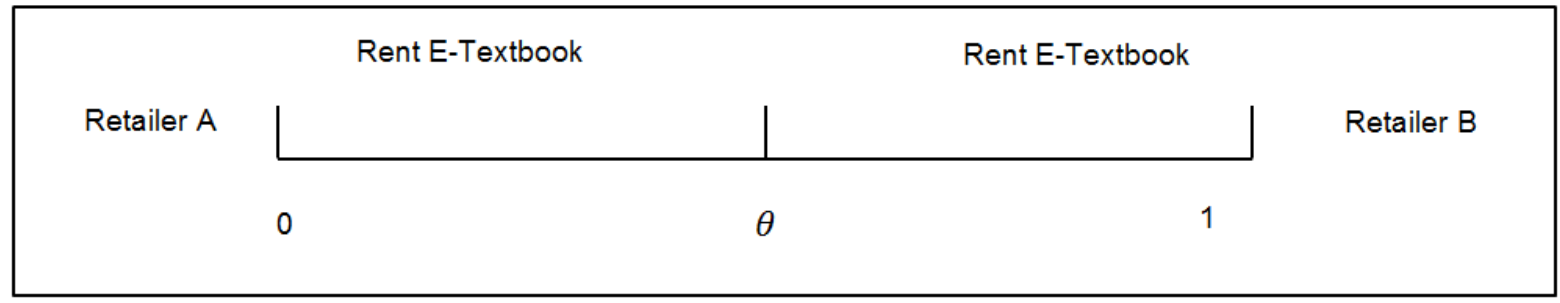

Figure 1: Market of e-textbook rental

At the indifference point, $v+s_{A}-k \theta-p_{A}^{e}-c_{e}=v+s_{B}-k(1-\theta)-p_{B}^{e}-c_{e}$. Thus, we have $\theta=\frac{s_{A}-s_{B}-p_{A}^{e}+p_{B}^{e}+k}{2 k}$. Solving the retailers' revenue function simultaneously, we get the following Lemma:

Lemma 1. The retailers' optimal price for the e-textbook rental and optimal revenue at equilibrium are as follows: for retailer $A p_{A}^{e *}=k+\frac{s_{A}-s_{B}}{3}$, and $\pi_{A}^{*}=\frac{\left(3 k+s_{A}-s_{B}\right)^{2}}{18 k}$; for retailer $B p_{B}^{e *}=k-\frac{s_{A}-s_{B}}{3}$ and $\pi_{B}^{*}=\frac{\left(3 k-s_{A}+s_{B}\right)^{2}}{18 k}$. (See Appendix A for proof)

Our next Lemma presents the impact of factors such as retailers' brand name recognition, and the transportation cost on the equilibrium outcome in Lemma 1.

Lemma 2. The leading retailer's price advantage will increase with the brand-name recognition gap; its revenue advantage will increase with the brand-name recognition gap but decrease with transportation cost. (Please see Appendix A for proof.)

The managerial insight from the two lemmas above is that the leading retailer such as Amazon's price advantage depends on the gap of its brand-name recognition and that of its competitor. Therefore, the leading retailer needs to develop an effective strategy to maintain higher brand-name recognition. In particular, it needs to identify the key factors of the differentiation strategy that will help keep its competitive advantage in pricing. For example, it can provide better service quality by designing with more attractive and flexible e-textbook rental options. It might also consider providing useful information such as consumers' input. Another possible method is to develop and improve features specially designed for e-textbook reading.

\section{Empirical Analysis}

We present in this section an empirical analysis using real business data of e-textbook rentals to investigate what factors of retailers' differentiation strategy might affect their pricing of digital content renting. We choose the etextbook rental market for the following reasons. First, it is a growing pay-per-use digital renting market. deNoyelles et al. (2015) found that students' use of e-textbook increased, and the coverage of consumers became broader demographically [18]. Over half of American college students have used e-textbook for at least one course. Second, e-textbooks are homogeneous products with the same delivery channel. This enables our analysis to address other quality dimensions understudied before such as service flexibility. Third, prior studies often used data at the market and retailer level, because data at these two levels is relatively easy to acquire [31]. Our data collection goes deeper into the textbook level, which enables us to better observe the difference between the leading retailer Amazon and the lesser-known retailer Chegg, and carry out multiple regression tests.

\subsection{E-textbook Rental Market}

We have witnessed rapid development of e-textbook rental market [18]. Online book giant retailer Amazon (Site 1) changed the college textbook model by starting an e-textbook rental program in September 2011 [46]. Students can rent e-textbooks at a much lower price, saving up to $90 \%$ compared with buying a hardcover copy. Amazon allows consumers to make multicolor highlighting, search inside the book, and use X-Ray application to manage the important concepts, definitions and notes in the textbook and related materials in Wikipedia and YouTube. Other value-added services include the option to extend the rental or purchase the e-textbook before the rental expires. The textbook rental startup Chegg (Site 2) also started his e-textbook rental program in January 2012. It claims that its EU reader gives students easy access to their rented e-textbooks while offering user-friendly features such as quick search, and notetaking. It also includes access to the supporting materials for free or free trial of the etextbook. An overview suggests that Amazon provides a little wider span in its e-textbook rental program. Table 2 below briefly compares the two retailers. 
Table 2: Comparison of Amazon's and Chegg's e-textbook rental program

\begin{tabular}{|l|l|l|}
\hline & Amazon & Chegg \\
\hline Starting Time & September 2011 & January 2012 \\
\hline Saving percentage & Up to 90\% & Up to 90\% \\
\hline Supporting & $\begin{array}{l}\text { Multiple options of renting length, specific } \\
\text { Service }\end{array}$ & $\begin{array}{l}\text { Multiple options of renting } \\
\text { length, specific designed }\end{array}$ \\
\hline Other model option to buy before the rental expires & Chegg e-textbook reader \\
\hline
\end{tabular}

Sources: Amazon (Site 1) and Chegg (Site 2)

\subsection{Hypothesis Development}

Based on related studies in e-commerce literature, we explore the key factors of retailers' differentiation strategy and their impact on retailers' rental price difference. We use the rental price difference to control the impacts of the unobserved factors such as popularity of the textbooks, and writing style [53]. It also helps test our horizontal model results. Previous studies showed that sellers vary in the service they provide for the consumers, which is often a source of differentiation [14], [21]. As mentioned earlier, e-textbook rental has both homogeneous content products and delivery channel. Therefore, retailers need to differentiate their service design which creates one more quality dimension for otherwise identical e-textbook rental options. In digital content renting, service flexibility becomes a viable differentiation strategy because it is always an important concern for students. Students can choose the option of textbooks such as e-textbook rental. For students renting the e-textbooks, they will get higher utility with more options of rental length available such as the options of returning the e-textbook to Amazon or Chegg every month until one year or 18 months. As a result, the e-textbook renting program with more service flexibility will be considered to be higher quality and leads to price advantage in the market. Prior research found the relationship between quality and the price difference across product types [25]. We suggest a similar case exists in the etextbook rental market. Generally, a positive relationship is expected between service flexibility difference of and retailers' rental price difference. Therefore, we propose the following hypothesis:

H1: The e-textbook rental price difference is positively associated with the difference of service flexibility level between the retailers.

Within the fast-growing e-textbook renting market, service design becomes a critical task for the retailer to build and maintain competitive advantage. In this digital rental market, service design is often reflected by another factor: starting return time, or the earliest time for students to return the e-textbooks. Contract plans' duration option often influences consumers' evaluation because consumers don't want to permanently keep this option [22]. Han et al. (2015) reported similar findings in the study of subscription length on consumers' renewal decision [27]. Students often need the e-textbook for just a few months rather than the whole academic year. If possible, students want to return it as soon as they finish using it. Consequently, the e-textbook renting program which offers an earlier returning time will be more attractive to students in their price discovery process. We argue that the earliest return time of the rented e-textbook is an important part of the service offered to the consumers. The retailer who offers earlier return time of the e-textbook rental program will have the price advantage. Therefore we propose the following hypothesis:

H2: The e-textbook rental price difference is negatively associated with the retailer's earliest return time. The later the earliest return time is, the lower the price advantage will be.

Retailers' price differentiation strategy also includes the incorporation of consumers' input. For each e-textbook web page on Amazon, we are able to observe consumers' ratings and the number of consumer raters. This gives us a good opportunity to analyze the impact of consumers' input on the retailers' price advantage. Reputation helps assess the trustworthiness of retailers/products in the e-commerce communities [31], [52]. User ratings are commonly considered an effective signal of consumers' trust [4]. In e-commerce areas such as sharing economy, consumers rely on the reputation system of online platforms such as Airbnb to determine hosts' ability, integrity and benefit [47]. Empirical analysis points out that reputation in terms of consumer scores can be translated into different prices [26].

We propose that in digital content renting such as e-textbook rental, reputational factors such as consumers' ratings play an important role in retailers' pricing. First, textbooks are experience goods. One will not be able to comment on the textbook until he/she reads it [15]. Naturally consumers want to know how previous users think of the textbook. Students used to have limited resources such as a discussion group. Now they have access to ratings and comments of previous users. Second, students have strong incentive to lower the risk of renting or buying textbooks, which makes reputational factors more salient. For the e-textbook with higher consumers' rating, there is room for the leading retailer to raise the price and gain a larger price advantage. Therefore we propose the following hypothesis:

H3: The e-textbook rental price difference is positively associated with the consumers' rating of the book. 
Products' reputation is often measured by both the magnitude of the consumers' ratings/score and in the number of raters/scorers [21], [47]. While consumers' rating gives a general idea on the textbook, the number of consumer raters/scorers might also play an important role. We suggest that a higher count of consumers' rating makes the rating more reliable for the consumers. Prior studies show that the amount of trust increases with a larger number of ratings [26]. A relatively small number of consumer raters might bring the concern of whether the rating is reliable and are the few raters really consumers of the textbook [47]. On the contrary, a larger number of consumer raters/scorers will increase consumers' confidence. Therefore, we propose the following hypothesis:

\section{H4: The e-textbook rental price difference is positively associated with the number of consumer raters/scorers of the} e-textbook.

We also examine retailers' different strategy of e-textbook selling price. While the leading retailer Amazon provides both selling price and rental price, Chegg limits e-textbook selling (only 3 out of 151 books have selling price). Prior research shows that the price of one product might impact the prices of related products in another format or version. Asai (2016) found that whether the novel also had a hardcover version or had been made into movies or TV drama had a significant impact on the paperback versions pricing [1]. The survey from Chao et al. (2016) of 432 respondents showed that for eight out of 11 variables, participants prefer movies streaming than DVD rental, which might influence the DVD rental price [11]. In the e-textbook market, higher selling price represents as an informative signal of the book value, which naturally influences consumers' price perception and leads to higher rental price. In addition, Amazon allows consumers to rent first and switch to purchase later, which reduces the risk and is more attractive compared with no such option available. Consequently, Amazon will be less pressured to join an intense price competition, and more likely keep the price advantage. Therefore we propose the following hypothesis:

\section{H5: The e-textbook rental price difference is positively associated with the e-textbook selling price.}

Our hypotheses are summarized in the following model (Figure 2). Investigating the drivers of the price advantage raises interesting theoretical issues. To test these hypotheses, we collected data and conducted a detailed analysis described in the next two subsections.

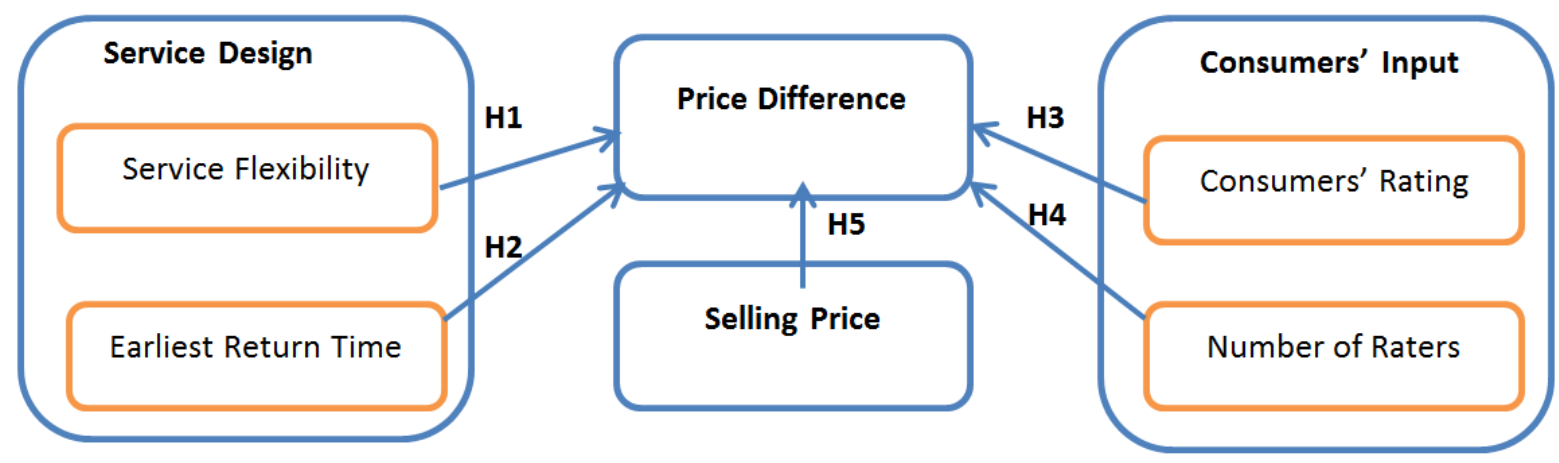

Figure 2: Conceptual model

\subsection{Data}

We collected data of 151 e-textbooks from two major online textbook rental retailers Amazon and Chegg in summer 2017. The textbooks we collected cover the five major areas of Business Administration of higher education institutions, including Accounting (31 books), Marketing (30 books), Finance (27 books), Management (34 books), and Operations Management and Information System Management (29 books). Our data set is of this size for several reasons. First, we want to develop a representative data-set of e-textbooks in the current market. Thus, we decided to exclude those e-textbooks published before 2010 which are relatively out of date or already in older editions. Second, compared with other types of books such as romance and history, the size of e-textbook is much smaller. In addition, many e-textbooks do not offer rental option due to the contracts between the publisher and the retailer. Third, we want to include those e-textbooks for which both retailers (Amazon and Chegg) offer rental option, which puts another restriction on the number of books available. Therefore, we consider our sample a representative one with a reasonable size. Prior studies use data sets with similar size. For example, Clay et al. (2002) used a data set of 107 books to study online and off-line book retailers' price competition [17]. Asai (2016) analyzed two data sets of Japanese books (one with 143 books and another with 111 books) [1]

For each e-textbook, we collect information available from both retailers (Amazon and Chegg) on the rental price with the earliest return time. This is the first price on the webpage consumers can see, from which consumers can estimate prices of other renting options. Listing price is often used in the studies of e-commerce literature [13], [17], [31], [47]. Prior research suggests that retailers' listing prices can be the proxy of the market transaction prices at the equilibrium [47]. We define rental flexibility in terms of the number of options of rental duration. For example, if the retailer offers rental of e-textbook for 60 days, 120 days, and 180 days, then the rental flexibility level for this e- 
textbook is 3. For each Amazon e-textbook, we also collect data on the consumers' rating on the textbook, the number of raters/scorers, and its selling price. In addition, we collect a list of control variables of book features, including the year of publication, the number of edition, the number of authors, and the number of pages. We also include a set of dummy variables to control the category of the e-textbook (which might have different patterns of price difference compared with other categories): D_ACCT , D_MKGT, D_FINC, and D_OPIM. For example, $D \_A C C T$ equals one when this is an accounting textbook, and zero otherwise.

To test hypothesis 1, we compute (SF-DIF) the difference of service flexibility between Amazon and Chegg on the same e-textbook with the collected data. To test hypotheses 2 and 3, we record the earliest return time and consumers' rating for each Amazon e-textbook. To test hypothesis 4, we take the log form of the consumer raters/scorers to control the expansion effect that textbooks might not have the same popularity level. This is a commonly used technique when few e-textbooks have a large number of raters/scorers while many other etextbooks have very few raters/scorers [47]. This is also consistent with our preliminary observation. To test hypothesis 5, we record Amazon's e-textbook selling price (we do not include the Chegg's e-book selling price because we only have prices of 3 out of 151 e-textbooks). Please see Table 3 below for the summary statistics of the collected data.

Table 3: Summary statistics

\begin{tabular}{|l|l|l|l|l|l|}
\hline Variable & Definition & Min & Average & Max & $\begin{array}{l}\text { Standard } \\
\text { Deviation }\end{array}$ \\
\hline SF_DIF & Service flexibility difference & 0.000 & 4.808 & 10.000 & 2.320 \\
\hline A_Speriod & Amazon earliest return time & 1.000 & 2.523 & 4.000 & 1.070 \\
\hline A_Rate & Consumer's rating & 2.400 & 3.922 & 5.000 & 0.408 \\
\hline A_RatersLOG & Log of the number of consumer raters & 0.000 & 1.338 & 2.709 & 0.580 \\
\hline A_Sell & Selling price of the textbook & 38.40 & 159.40 & 262.50 & 51.495 \\
\hline Year & Publishing year & 2010 & 2014 & 2017 & 1.468 \\
\hline Edition & Number of edition & 1.000 & 8.868 & 40.000 & 5.766 \\
\hline No_Author & Number of authors & 1.000 & 2.245 & 5.000 & 0.931 \\
\hline Pages & Number of pages & 288 & 697.100 & 1760 & 218.343 \\
\hline D_ACCT & $\begin{array}{l}\text { Dummy variable: } 1 \text { for Accounting textbook, } \\
\text { O otherwise }\end{array}$ & 0 & 0.205 & 1 & 0.405 \\
\hline D_MKGT & $\begin{array}{l}\text { Dummy variable: } 1 \text { for Marketing textbook, 0 } \\
\text { otherwise }\end{array}$ & 0 & 0.199 & 1 & 0.400 \\
\hline D_FINC & $\begin{array}{l}\text { Dummy variable: } 1 \text { for Finance textbook, 0 } \\
\text { otherwise }\end{array}$ & 0 & 0.179 & 1 & 0.384 \\
\hline D_OPIM & $\begin{array}{l}\text { Dummy variable: } 1 \text { for Operations and } \\
\text { Information Management textbook, 0 } \\
\text { otherwise }\end{array}$ & 0 & 0.192 & 1 & 0.395 \\
\hline
\end{tabular}

Multiple unobserved factors related to book heterogeneity might influence the price of e-textbook such as quality of resources and authors, popularity of the content, writing style, and marketing effort. We define the dependent variable (Price_DIF) as the difference of rental price of the same e-textbook from Amazon and Chegg so the impact of these unobserved factors cancels out when we take the difference [53]. Therefore, our model is as follows:

$$
\text { Price_DIF }=\beta_{0}+\beta_{1} S F \_D I F+\beta_{2} A_{-} \text {Speriod }+\beta_{3} A_{-} \text {Rate }+\beta_{4} \text { A_RatersLOG }+\beta_{5} \text { A_Sell }+ \text { Control }+\varepsilon
$$

We have checked the correlation values among those independent variables and found that there is no extremely high value that implies too close of a relationship. Additionally, we applied Variance inflation factors (VIF) to check the multicollinearity between independent variables for any undesired effects on the regression results. Since all VIF values are less than 2.0 except one variable D-ACCT (2.093), multicollinearity hence is not an issue here.

\subsection{Results}

Our analysis has addressed several difficult issues in theory testing. First, while price dispersion is usually measured by the market level [21], our unique data set allows us to observe the retailers' e-textbook rental competition at the textbook level. For the same e-textbook, we are able to observe the differences not only in the retailers' rental prices but also in their service design. Second, the current study provides more comprehensive tests of the impact of factors on pricing difference. To assess the robustness of the hypotheses, we conduct multiple regression analysis with varying sets of control variables. We present four models in our study. In Model 1, we only include the five independent variables: $S F_{-} D I F, A_{-}$Speriod, $A_{-}$Rate, $A_{-}$RatersLOG, and $A_{-} S e l l$. In Model 2, we include the five independent variables together with control variables related to textbook features: publishing year, number of edition, number of authors, and number of pages. In Model 3, we include the five independent variables together with dummy variables of the textbook category: $D_{-} A C C T, D_{-} M K G T, D_{-} F I N C$, and $D_{-} O P I M$. In Model 4 , we include the five independent variables together with both the control variables related to the textbook features and the dummy variables of the textbook category. Table 4 below summarizes the results of our regression analysis. 
Table 4: Summary of regression analysis (Standard errors in the parentheses)

\begin{tabular}{|c|c|c|c|c|}
\hline & Model 1 & Model 2 & Model 3 & Model 4 \\
\hline Intercept & $\begin{array}{l}-25.604 \\
(7.348)^{\star \star \star}\end{array}$ & $\begin{array}{l}1110 \\
(1007)\end{array}$ & $\begin{array}{l}-28.181 \\
(7.691)^{\star \star *}\end{array}$ & $\begin{array}{l}1318 \\
(1027)\end{array}$ \\
\hline Service flexibility difference & $\begin{array}{l}0.883 \\
(0.408)^{*}\end{array}$ & $\begin{array}{l}0.855 \\
(0.411)^{*}\end{array}$ & $\begin{array}{l}0.875 \\
(0.415)^{*}\end{array}$ & $\begin{array}{l}0.835 \\
(0.419)^{*}\end{array}$ \\
\hline Earliest return time & $\begin{array}{l}-4.276 \\
(0.849)^{\star * *}\end{array}$ & $\begin{array}{l}-3.688 \\
(0.884)^{\star \star *}\end{array}$ & $\begin{array}{l}4.355 \\
(0.863)^{\star \star \star}\end{array}$ & $\begin{array}{l}-3.734 \\
(0.885)^{\star \star \star}\end{array}$ \\
\hline Consumers' rating & $\begin{array}{l}6.730 \\
(1.863)^{\star * \star}\end{array}$ & $\begin{array}{l}5.771 \\
(1.855)^{\star \star}\end{array}$ & $\begin{array}{l}7.227 \\
(1.901)^{\star * *}\end{array}$ & $\begin{array}{l}6.194 \\
(1.862)^{\star *}\end{array}$ \\
\hline Number of consumer raters & $\begin{array}{c}-1.849 \\
(1.314)\end{array}$ & $\begin{array}{l}-0.723 \\
(1.354)\end{array}$ & $\begin{array}{l}-1.286 \\
(1.375)\end{array}$ & $\begin{array}{l}0.453 \\
(1.427)\end{array}$ \\
\hline Selling price & $\begin{array}{l}0.106 \\
(0.016)^{\star * *}\end{array}$ & $\begin{array}{l}0.127 \\
(0.017)^{\star * *}\end{array}$ & $\begin{array}{l}0.096 \\
(0.018)^{\star * *}\end{array}$ & $\begin{array}{l}0.114 \\
(0.018)^{\star * *}\end{array}$ \\
\hline Year of publication & & $\begin{array}{l}-0.560 \\
(0.499)\end{array}$ & & $\begin{array}{l}-0.664 \\
(0.510)\end{array}$ \\
\hline Number of edition & & $\begin{array}{l}-0.026 \\
(0.152)\end{array}$ & & $\begin{array}{l}-0.026 \\
(0.157)\end{array}$ \\
\hline Number of authors & & $\begin{array}{l}-0.406 \\
(0.799)\end{array}$ & & $\begin{array}{l}-0.455 \\
(0.797)\end{array}$ \\
\hline Number of pages & & $\begin{array}{l}-0.013 \\
(0.004)^{\star * *}\end{array}$ & & $\begin{array}{l}-0.015 \\
(0.004)^{\star * *}\end{array}$ \\
\hline D_OPIM & & & $\begin{array}{l}1.437 \\
(1.796)\end{array}$ & $\begin{array}{l}1.796 \\
(2.253)\end{array}$ \\
\hline D_ACCT & & & $\begin{array}{l}3.650 \\
(2.491)\end{array}$ & $\begin{array}{l}6.171 \\
(2.458)^{*}\end{array}$ \\
\hline D_MKGT & & & $\begin{array}{l}2.358 \\
(2.281)\end{array}$ & $\begin{array}{l}2.637 \\
(2.217)\end{array}$ \\
\hline D_FINC & & & $\begin{array}{l}0.502 \\
(2.339)\end{array}$ & $\begin{array}{l}2.149 \\
(2.293)\end{array}$ \\
\hline Adjusted R-square & 0.4409 & 0.4785 & 0.4362 & 0.4874 \\
\hline
\end{tabular}

Note: ${ }^{* * *} p<0.001^{* *} p<0.01^{*} p<0.05$

We first examine the impact of service design. Regarding the difference of retailers' service flexibility, we find that this factor does significantly and positively influence the retailers' e-textbook rental price difference in all four models $(p<0.05)$. Therefore $\mathrm{H} 1$ is supported. This finding implies that retailers do consider service flexibility as a key component of their differentiation strategy. Since e-textbook rental is homogeneous in content and delivery channel, the retailers need to figure out other ways to distinguish themselves. Service design can be an effective way to reflect seller heterogeneity which functions similar to the strategy of providing different delivery options of physical products analyzed in previous empirical studies [20], [37]. Flexible rental length option becomes attractive to consumers who favor more service flexibility, thus influencing their price perception. We find that Chegg often only provides five levels of renting durations: 60 days, 90 days, 120 days, 180 days, and 360 days while Amazon provides higher service flexibility. A recommendation from this finding is that Chegg might consider increasing levels of rental length options. On the other hand, Amazon can highlight the higher service flexibility in its rental program.

We also find evidence which shows the earliest returning time is a key driver for retailers' e-textbook rental price difference ( $p<0.001$ for all four models). The longer consumers need to wait to return their rented e-textbook, the smaller the price difference will be. It offers support for $\mathrm{H} 2$. Our finding implies that the earliest returning time can be a key service design feature to distinguish a retailer's e-textbook rental program. As is easily observed by consumers, the earliest returning time appears to play an important role on consumers' utility of the e-textbook rental and their willingness to pay, just like the case of music as a service (Maas) [22] and the e-book subscription [27]. Therefore, retailers need to incorporate consumers' needs in the service design to keep their price advantage. Amazon might consider further shortening the current earliest return time (30 days) to attract more consumers.

Then we examine the retailers' differentiation strategy of providing additional information such as consumers' inputs. While Amazon provides consumers' reviews/ratings and number of raters, Chegg doesn't incorporate ratings in its program. We first check the impact of consumers' ratings. Our results in all four models show that e-textbooks with higher consumer ratings will bring significant e-textbook rental pricing difference $(\mathrm{p}<0.01)$. It offers support for $\mathrm{H} 3$. This finding demonstrates the important role of consumer's rating in retailers' pricing strategy, which is similar to the results of previous studies in online markets [21], [31] and sharing economy [23], [47]. Our analysis goes one step further to clearly present this impact at the e-textbook level. When an e-textbook enjoys higher popularity, such effect becomes more obvious and the retailer might benefit with a higher rental price advantage. Our results suggest that Amazon needs to continue encouraging consumers to give ratings on the rented e-textbook. Meanwhile, Chegg might consider adding the consumers' ratings on the e-textbook rental web page. 
With regard to the number of consumer raters/scorers, surprisingly, we have seen negative (although not significant) impact in three out of four models. Therefore, $\mathrm{H} 4$ is not supported. The common notion that the number of consumer raters/scorers is a key impact factor does not hold. There may be several reasons for this seemingly counterintuitive result. One possibility is that consumers are more interested in the overall rating than the number of raters/scorers, or consumers with low evaluation are more likely to rate the e-textbook. Another possible explanation is that consumers have not noticed such information because it is listed on the lower part of the webpage as the case for Amazon. A similar finding is reported on the impact of the number of consumer raters on hotel pricing in the sharing market [47]. A recommendation from this finding is that Amazon might highlight the number of raters on its web pages.

Next, we analyze the impact of providing e-textbook selling price. Evidence is found that the e-textbook selling price exerts a significant and positive influence on the pricing difference in all four models $(p<0.001)$, so H5 is supported. This finding suggests that retailers' positive signal of book value (higher selling price) helps promote the e-textbook rental for the same book. As a result, retailers might achieve price advantage in the market. This is consistent with the finding of the relationship between free and premium online game service [29]. In addition, this finding reflects that the retailer with the value added option of switching from rental to purchase is able to increase consumers' price perception for the e-textbook rental. Overall, our results gave consistent and significant support to most of the proposed hypotheses. We summarize the results of hypothesis testing in the following table.

Table 5: Summary of hypotheses testing results

\begin{tabular}{|l|l|}
\hline Hypothesis & Support? \\
\hline $\begin{array}{l}\text { H1. The e-textbook rental price difference is positively associated with the difference of service } \\
\text { flexibility level between the retailers. }\end{array}$ & Yes \\
\hline $\begin{array}{l}\text { H2. The e-textbook rental price difference is negatively associated with the leading retailer's } \\
\text { earliest return time. The later the earliest return time is, the lower the price advantage will be. }\end{array}$ & Yes \\
\hline $\begin{array}{l}\text { H3. The e-textbook rental price difference is positively associated with the consumers rating of the } \\
\text { book. }\end{array}$ & Yes \\
\hline $\begin{array}{l}\text { H4. The e-textbook rental price difference is positively associated with the number of consumer } \\
\text { raters/scorers of the e-textbook. }\end{array}$ & No \\
\hline H5. The e-textbook rental price difference is positively associated with the e-textbook selling price. & Yes \\
\hline
\end{tabular}

In addition, our results show that the amount of the unexplained variance in our model is almost $50 \%$ in all four models. Previous research reported similar results with adjusted R-square values less than $40 \%$ in all six models [47]. It is possible that the unexplained variance might be from customer loyalty, reputation, and customer service.

\section{Theoretical Contributions and Practical Implications}

This research is one of the pioneering studies exploring retailers' differentiation strategy in the online digital content renting market. The unique data set of 151 e-textbook rentals enables us to examine the key elements of retailers' strategy for price advantage. Our study complements the prior research in the following three aspects:

First, our research enriches the e-commerce literature by extending the analysis of online renting model into the area of pay-per-use digital goods such as e-textbooks. Current research on digital content renting mainly focuses on the subscription model [25], [35], [42]. However, research on pay-per-use digital renting especially related empirical analysis is scarce. This study, different from most previous research in this area, investigates how retailers of payper-use digital content rental can differentiate themselves for price advantage in the market. This paper has confirmed an important belief that retailers do need differentiation strategies to maintain their price advantage. We expect to see more researchers will switch to the digital renting content model in the pay-per-use setting. Our findings can be applied to a broad range of rental programs of digital goods. For example, education software vendors provide specific software for students to rent as additional resources in courses such as statistics. Based on our findings, these vendors may consider providing more flexibility of renting the software. In addition, retailers such as YouTube allow consumers to rent newly released movies, TV series, and shows. They can incorporate consumer's ratings in their renting service.

Second, our research enhances the current understanding of retailers' e-textbook rental strategy especially the differentiation strategy in the market. This is one of the first attempts to analyze the impact of previously understudied factors such as service design and consumers' input. We carry out an empirical analysis using data of 151 e-textbook from two major online textbook rental retailers (Amazon and Chegg) to make specific assessments of the impact of these differentiation dimensions. We find that service flexibility, earliest return time and the consumers' rating will strengthen the leading retailer's price advantage. The results show the importance of service quality in the rental market of digital goods, which is consistent with quality-based price discrimination theory [20]. The important factors identified in the current study will aid firms in the online content renting market. This study consolidates the prior research and builds a foundation for future research in this area. Other researchers can start by looking at other important but understudied factors. 
Third, we add to the literature with important insights into the strategies of digital content renting retailer under the competition setting. The extant research on digital content renting/subscription usually focuses on decisions of firms under non-competition settings [25], [35], [42]. However, our observation shows that competition setting better reflects the current market dynamics as is the case with the competition between Amazon and Chegg. Analysis of retailers' strategy in competition provides us with much deeper and richer insights. For example, we provide important insights for the retailers in that the factors highlighted by our findings can affect the way retailers price their products as compared with other competitors in the market. This type of decision might not be an issue for the retail in the non-competition market setting.

In addition, our research provides practical implications for retailers in the following three aspects:

First, our study shows that retailers need to keep improving the service quality of their e-textbook renting program. The leading retailer such as Amazon can design better service to encourage more consumers to choose its etextbook rental program. For example, it can design more flexible rental options for students and allow consumers to return the rented e-textbook earlier. Other possible tactics include making the e-textbook reading more comfortable, providing audible navigation service options, and encouraging interactions with consumers. Overall, our findings demonstrate the importance of service quality of retailers' e-textbook rental program.

Second, our findings show that retailers' incorporation of consumer's inputs is beneficial. The effect of consumers rating /reputation on price is well supported by both theoretical and empirical work [14]. Interestingly, the factor of the number of consumer raters/scorers does not show a significant impact. A corresponding recommendation of our finding is that retailers need to attract more consumers and use their inputs more efficiently. For the leading retailer such as Amazon who has already developed the consumer's rating system, it needs to think about maintaining this advantage. For example, Amazon can encourage consumers to make useful comments by offering discounts/coupons or other kinds of rewards. For the lesser-known retailer such as Chegg, it needs to catch up and reduce the gap. Chegg might consider setting up its own consumers' rating program immediately. In addition, it may further optimize the program with social media support and live chat, and create an e-textbook commenter community to attract consumer raters.

Third, our study tells retailers that e-textbook features might also have a significant impact on the price difference. For example, in model 4 of the previous section, we can see that the type of accounting e-textbooks and the number of pages of e-textbooks have significantly influenced the leading retailer's price advantage. This finding reminds the retailer to consider those textbook features based on the historical sales record of different types of e-textbooks. The summary of the theoretical contributions and practical implications is listed in Table 6.

Table 6: Summary of theoretical contributions and practical implications

\begin{tabular}{l}
\hline Theoretical Contributions \\
\hline 1. Enriching the e-commerce literature by extending \\
the analysis of online renting model into the area of \\
pay-per-use digital goods such as e-textbooks \\
2. Enhancing the current understanding of retailers' \\
e-textbook rental strategy especially the \\
differentiation strategy in the market. \\
3. Adding to the literature with important insights into \\
the strategies of digital content renting retailer under \\
the competition setting.
\end{tabular}

Theoretical Contributions

1. Enriching the e-commerce literature by extending pay-per-use digital goods such as e-textbooks e-textbook rental strategy especially the differentiation strategy in the market.

the competition setting.

\section{Conclusion}

This study is inspired by the growing popularity of online renting of digital content. Following the trend of rental models, online textbook retailers have recently introduced the e-textbook rental model in the fast-growing textbook rental market. This critical strategic decision brings new competition, and requests to retailers for specified differentiation strategy in the rental market. Our research sheds light on the impact of specific price drivers that contributes to retailers' e-textbook rental price difference in the market. A horizontal model reflecting the market competition dynamics suggests that non-price factors such as service quality are critical for the leading retailer to keep the price advantage. Based on a unique data set of 151 e-textbooks from two major retailers Amazon and Chegg, we are able to conduct a set of regression analysis to test our proposed hypotheses on the impact of retailers' service design, consumers' input, and e-textbook selling price. The results from our empirical analysis are consistent with most of our hypotheses that those factors have a significant impact on retailers' pricing differences.

Our research has a few limitations. First, we haven't taken publishers' strategy into account. One reason is that the relationship between publisher and retailer is changing continually and dynamically. For example, major publishers have recently developed an agency model with retailers such as Amazon, which gives them the power to pre-set the price. Second, we haven't considered the depreciation of digital content value over time, which might change consumers' behavior. For example, the value of e-textbook will decrease when new versions of the textbook are 
introduced in the market. Finally, our data collection is only limited to listing prices from Amazon and Chegg. If both retailers make the transaction prices available in public, we can expand our data set which will benefit future studies.

Future research can be extended in the following ways. First, both our horizontal model and empirical analysis include only a leading retailer (Amazon) and a lesser-known retailer (Chegg) in a competitive environment. However, the textbook rental market continues to grow and can be more complex in the future. In that case, either a theoretical model or an empirical analysis incorporating more retailers can be an interesting extension of our research, which will enhance our understanding of the digital content renting market. Second, if we can collect data on the consumer level measurements such as consumer loyalty and customer service quality, we might be able to explore unexplained variance in our future analysis. Third, future research can consider further exploring individual textbook features such as the type and the size of the textbooks. If a larger dataset is available, it will be interesting to see whether there will be any changes in both the direction and the significance of the independent and control variables in the model. Lastly, as mentioned earlier in the paper, we have not considered the e-textbook reselling. It will be interesting for future research to explore how the e-textbook reselling market impacts retailers' strategy.

\section{Websites list}

Site 1: Amazon

www.Amazon.com

Site 2: Chegg

www.Chegg.com

\section{References}

[1] S. Asai, Determinants of demand and price for best-selling novels in paperback in Japan, Journal of Culture Economics, vol. 40, no. 4, pp. 375-392, 2016.

[2] J. P. Bailey, S. Faraj and Y. Yao, The road more travelled: Web traffic and price competition in internet retailing, Electronic Markets, vol. 17, no. 1, pp. 56-67, 2007.

[3] O. Baris and L. Kutlu, Price dispersion and optimal price categories with limited memory consumers, Managerial and Decision Economics, vol. 39, no. 1, pp. 97-106, 2018.

[4] G. Bente, O. Baptist and H. Leuschner, To buy or not to buy: Influence of seller photos and reputation on buyer trust and purchase behavior, International Journal of Human Computer Studies, vol. 70, no. 1, pp. 1-13, 2012.

[5] B. Berger, C. Matt, D. Steininger, and T. Hess, It is not just about competition with free: Differences between content formats in consumer preferences and willingness to pay, Journal of Management Information Systems, vol. 32, no.3, pp. 105-128, 2015.

[6] D. Bounie, B. Eang, M. A. Sirbu, and P. Waelbroeck, Superstars and outsiders in online markets: An empirical analysis of electronic books, Electronic Commerce Research and Applications, vol. 12, no. 1, pp. 52-59, 2013.

[7] BusinessWire. (2017, December) Global e-textbook rental market - Cost-effective pricing | Technavio. Businesswire. [Online]. Available: https://www.businesswire.com/news/home/20171202005025/en/Global-ETextbook-Rental-Market-Cost-Effective-Pricing

[8] A. Carrns. (2014, August) A quandary for textbooks: Whether to buy or rent. New York Times. [Online]. Available: https://www.nytimes.com/2014/08/09/your-money/Textbooks-whether-to-buy-or-rent.html

[9] A. Carrns. (2016, September) A new cost at college: Digital access codes. New York Times. [Online]. Available: https://www.nytimes.com/2016/09/24/your-money/a-new-cost-at-college-digital-access-codes.html

[10] C. Chao, L. Fuxman and H. Elifoglu, Electronic books impact global environment-An empirical study focus on user perspectives, Journal of Management and Strategy, vol. 4, no. 2, pp. 52-59, 2013.

[11] C. Chao, N. Hegarty and I. Fray, Impact of movie streaming over traditional DVD movie rental-An empirical study, Journal of Industrial and Intelligent Information, vol. 4, no. 2, pp.104-109, 2016.

[12] R. K. Chellappa and K. R. Kumar, Examining the role of 'free' product-augmenting online services in pricing and customer retention strategies, Journal of Management Information Systems, vol. 22, no. 1, pp. 355-377, 2005.

[13] J. Chevalier and A. Goolsbee, Measuring price and price competition online: Amazon and Barnes \& Noble, Quantitative Marketing and Economics, vol. 1, no. 2, pp. 203-222, 2003.

[14] J. Chen, Pricing strategy, in The Electronic Market (F. J. Martínez-López, Ed.). New York, United States, Handbook of Strategic e-Business Management, 2014, pp. 489-522.

[15] L. Chen, A quantitative analysis on e-book sampling optimization, Journal of Theoretical and Applied Electronic Commerce Research, vol. 12, no. 1, pp. 68-76, 2017.

[16] L. Chen and R. King, To lend is to own: A game theoretic analysis of the e-book lending market, International Journal of Electronic Commerce, vol. 21, no. 3, pp. 334-362, 2017.

[17] K. Clay, R. Krishnan, E. Wolff, and D. Fernandes, Retail strategies on the web: Price and non-price competition in the online book industry, The Journal of Industrial Economics, vol. 50, no. 3, pp. 351-367, 2002.

[18] A. deNoyelles, J. Raible and R. Seilhamer, (2015, July) Exploring students' e-textbook practice in higher education. Educase. [Online]. Available: https://er.educause.edu/articles/2015/7/exploring-students-etextbookpractices-in-higher-education 
[19] Y. Ding, X. Gao, C. Huang, J. Shu, and D. Yang, Service competition in an online duopoly market, Omega, vol. 77 , pp. 58-72, 2018

[20] E. M. Dinlersoz and H. Li, The shipping strategies of internet retailers: Evidence from internet book retailing, Quantitative Marketing and Economics, vol. 4, no. 4, pp. 407-438, 2006.

[21] D. DiRusso, S. Mudambi and D. Schuff, Determinants of prices in an online marketplace, Journal of Product and Brand Management, vol. 20, no. 5, pp. 420-428, 2011.

[22] J. Doerr, A. Benlian, J. Vetter, and T. Hess, Pricing of content services-an empirical problem investigation of music as a service, in Proceeding of 16 th Americas Conference on Information Systems, track of Sustainable e-Business Management, Lima, Peru, LNBIP 58, 2010, pp. 13-24.

[23] B. Edelman and M. Luca, Digital discrimination: The case of Airbnb.com, Harvard Business School NOM Unit Working Paper, No. 14-054, 2014

[24] G. Ellison and S. Ellison, Search, obfuscation, and price elasticities on the Internet, Econometrica, vol. 77, no. 2, pp. 427-452, 2009.

[25] V. Grover, J. Lim and R. Ayyagari, The dark side of information and market efficiency in e-markets, Decision Sciences, vol. 37, no. 3, pp. 297-324, 2006

[26] G. Guo, J. Zhang, D. Thalmann, A. Basu, and N. Yorke-Smith, From ratings to trust: An empirical study of implicit trust in recommender systems, in Proceedings Symposium on Applied Computing, Gyeongju, Republic of Korea, 2014, pp. 248-253.

[27] S. Han, J. Hong, J. Moon and W. Oh, The economics of all-you-can-read pricing: Tariff choice, contract renewal, and switching for e-book purchases, in Proceeding of International Conference of Information Systems, Fort Worth, TX United States, 2015.

[28] L. Hao and M. Fan, An analysis of pricing models in the electronic book market, MIS Quarterly, vol. 38, no. 4, pp. 1017-1032, 2014.

[29] J. Hamari, N. Hanner and J. Koivisto, Service quality explains why people use freemium services but not if they go premium: An empirical study in free-to-play games, International Journal of Information Management, vol. 37, no. 1, pp. 1449-1459, 2017.

[30] M. Hviid and G. Shaffer, Matching own prices, rivals' prices, or both? Journal of Industrial Economics, vol. 58, no. 3, pp. 479-506, 2010 .

[31] G. Joliveta, B. Jullienb and F. Postel-Vinaycde, Reputation and prices on the e-market: Evidence from a major French platform, International Journal of Industrial Organization, vol.45, no. 1, pp.59-75, 2016.

[32] T. Keskin and N. Taskin, Strategic pricing of horizontally differentiated services with switching costs: A pricing model for cloud computing, International Journal of Electronic Commerce, vol. 19, no. 3, pp. 34-53, 2015.

[33] P. King. (2009, April) A textbook case of renting books. Wall Street Journal. [Online]. Available: https://www.wsj.com/articles/SB124045232885846381

[34] A. Lambrecht, A. Goldfarb, A. Bonatti, A. Ghose, D. Goldstein, R. Lewis, A. Rao, N. Sahni, and Y. Song, How do firms make money selling digital goods online? Marketing Letters, vol. 25, no. 3, pp. 331-341, 2014

[35] A. Lambrecht and K. Misra, Fee or free: When should firms charge for online content? Management Science, vol. 63, no. 4, pp. 1150-1165, 2017.

[36] D. Li, K. Goh and C. Heng, Price competition and demand for online content: Uncovering the role of content differentiation and network structure, in Proceedings of International Conference of Information Systems, Seoul, South Korea, 2017.

[37] $\mathrm{H}$. Li and E. Dinlersoz, Quality based price discrimination: Evidence from Internet retailers shipping options Journal of Retailing, vol. 88, no. 2, pp. 276-290, 2012.

[38] Y. Li, Z. Lin, L. Xu, and A. Swain, Do the electronic books reinforce the dynamics of book supply chain market? An theoretical analysis, European Journal of Operational Research, vol. 245, no. 2, pp. 591-601, 2015.

[39] K. Lyons, P. R. Messinger, R. Niu, and E. Stroulia, A tale of two pricing systems for services, Information Systems and E-Business Management, vol. 10, no. 1, pp. 19-42, 2012.

[40] J. Miller, A. Nutting and L. Baker, The determinants of electronic textbook use among college students, The American Economics, vol. 58, no.1, pp. 41-50, 2013.

[41] J. Mitchell. (2014, August) A tough lesson for college textbook retailers. Wall Street Journal. [Online]. Available: https://www.wsi.com/articles/a-tough-lesson-for-college-textbook-publishers-1409182139

[42] H. Oh, A. Animesh and A. Pinsonneault, Free versus for-a-fee: the Impact of paywall on the pattern and effectiveness of word-of-mouth via social media, MIS quarterly, vol. 40, no. 1, pp. 31-56, 2016.

[43] E. Overby and C. Forman, The effect of electronic commerce on geographic purchasing patterns and price dispersion, Management Science, vol. 61, no. 2, pp. 431-453, 2014.

[44] A. Rao, Online content pricing: Purchase and rental markets, Marketing Science, vol. 34, no. 3, pp. 430-451, 2015.

[45] R. Renolds, Trends influencing the growth of digital textbooks in US Higher Education, Publishing Research Quarterly, vol. 27, no. 2, pp. 178-187, 2011.

[46] P. Sloan. (2012, August) Amazon goes for college crowd, launches rental textbook service. CNet. [Online]. Available: https://www.cnet.com/news/amazon-goes-for-college-crowd-launches-rental-textbook-service/

[47] T. Teubner, F. Hawlitschek and D. Dann, Price determinants on Airbnb: How reputation pays off in the sharing economy, Journal of Self-Governance and Management Economics, vol. 5, no. 4, pp. 53-80, 2017.

[48] D. Vernik, D. Purohit and P. Desai, Music downloads and the flip side of digital rights management, Marketing Science, vol. 30, no. 6, pp. 1011-1027, 2011

[49] T. M. Wagner, A. Benlian and T. Hess, Converting freemium customers from free to premium-The role of the perceived premium fit in the case of music as a service, Electronic Markets, vol. 24, no. 4, pp. 259-268, 2014. 
[50] S. Wattal, R. Telang and T. Mukhopadhyay, Information personalization in a two-dimensional product differentiation model, Journal of Management Information Systems, vol. 26, no. 2, pp. 69-95, 2009.

[51] S. Wu and R. Banker, Best pricing strategy for information services, Journal of Association of Information Systems, vol. 11, no. 6, pp. 339-366, 2010.

[52] L. Xiong and L. Liu, Peertrust: Supporting reputation-based trust for peer-to-peer electronic communities, IEEE Transactions on Knowledge and Data Engineering, vol. 16, no. 7, pp. 843-857, 2004.

[53] J. Wooldridge, Introductory Econometrics: A Modern Approach. Nashville, United States, South-Western College Pub; 2nd edition, 2002.

[54] J. Zhang and A. Seidmann, Perpetual versus subscription licensing under quality uncertainty and network externality effects, Journal of Management Information Systems, vol. 27, no. 1, pp. 39-68, 2010. 


\section{Appendix A: Proof of Lemmas}

\section{Proof of Lemma 1}

In this case, retailer A's revenue function is as follows:

In this case, retailer B's revenue function is as follows:

$$
\pi_{A}=\left(\frac{s_{A}-s_{B}-p_{A}^{e}+p_{B}^{e}+k}{2 k}\right) p_{A}^{e}
$$

$$
\pi_{B}=\left(1-\frac{s_{A}-s_{B}-p_{A}^{e}+p_{B}^{e}+k}{2 k}\right) p_{B}^{e}
$$

Then we compute the two first order conditions (FOC) $\frac{\partial \pi_{A}}{\partial p_{A}^{e}}=0$ and $\frac{\partial \pi_{B}}{\partial p_{B}^{e}}=0$. We solve them together to get the results of Lemma 1: $p_{A}^{e *}=k+\frac{s_{A}-s_{B}}{3}$, and $\pi_{A}^{*}=\frac{\left(3 k+s_{A}-s_{B}\right)^{2}}{18 k} ; p_{B}^{e *}=k-\frac{s_{A}-s_{B}}{3}$ and $\pi_{B}^{*}=\frac{\left(3 k-s_{A}+s_{B}\right)^{2}}{18 k}, \theta_{1}=\frac{s_{A}-S_{B}+3 k}{6 k}$.

\section{Proof of Lemma 2}

The comparative static for the equilibrium results in Lemma 1 shows the following: Let the price difference $\Delta p=p_{A}^{e *}-p_{B}^{e *}, \Delta s=s_{A}-s_{B}$. Therefore, we have $\frac{\partial \Delta p}{\partial \Delta s}>0$. Let the revenue difference $\Delta \pi=\pi_{A}^{2 *}-\pi_{A}^{1 *}$. Therefore, we have $\frac{\partial \Delta \pi}{\partial \Delta s}>0$, and $\frac{\partial \Delta \pi}{\partial k}<0$. 